\title{
Inhaltsverzeichnis
}

Vorbemerkungen ........................ . 5

Verzeichnis der Abbildungen . . . . . . . . . . . . . . . . . . . . . . . 7

Verzeichnis der Abkürzungen . . . . . . . . . . . . . . . . . . . . . 9

I. Bemerkungen zu den meroitischen Totentexten . . . . . . . . . . . . . 11

1. „Opfertafeln" und ,Stelen" . . . . . . . . . . . . . . . . . . . . 11

2. Aufbau und Entwicklung der Texte . . . . . . . . . . . . . . . . . 12

3. Die Wiederholung der (B)- und (C)-Wörter in der "Nomination“ . . . . 13

II. „Kambesweden“ und die Regierungszeit des Nastaseñ . . . . . . . . . 17

III. Bemerkungen zur Chronologie der Herrscher von Meroe . . . . . . . . . 21

1. Die Periode von Aspelta bis Ergamenes . . . . . . . . . . . . . . 22

2. Die Periode von Tabirqa bis TeqĒrideamani . . . . . . . . . . . . 24

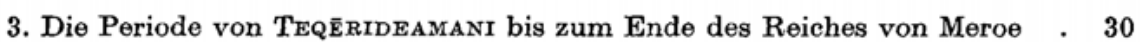

4. Liste der Herrscher von Meroe von Tabirqa bis zum Ende des Reiches . . 32

IV. Die Opfertafeln aus den Pyramiden von Meroe . . . . . . . . . . . . . 34

1. Aufbau der Texte und Formeln . . . . . . . . . . . . . . . . . . . 34

a) Die Formel K . . . . . . . . . . . . . . . . . . . . . . . . . 34

b) Die Formel L . . . . . . . . . . . . . . . . . . . . . . . . . . 34

c) Die Formel $\mathbf{C}^{\prime}$. . . . . . . . . . . . . . . . . . . . . . . . . 35

d) Die Formelfolge . . . . . . . . . . . . . . . . . . . . . . . . 35

e) Die Affixe beim Verbum . . . . . . . . . . . . . . . . . 35

f) $\mathrm{Die}$ (B)- und (C)-Wörter . . . . . . . . . . . . . . . . . . . . . 35

2. Die Texte . . . . . . . . . . . . . . . . . . . . . . . . . . . 36

A. Die Opfertafeln der Herrscher . . . . . . . . . . . . . . . . . . 36

1 . . . . . . . . . . . . . . . . . . . . . 36

2 . . . . . . . . . . . . . . . 39

3.......................... . . 40

$4 . \ldots . . . . . . . . .41$

5 ........................441

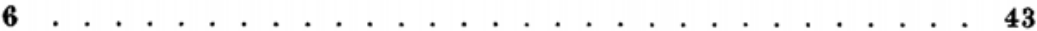

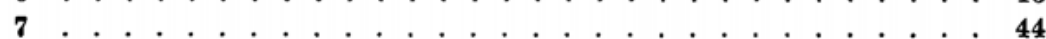

8a......................... . . . 45

$8 \mathrm{~b} . . . . . . . . . . . . . . . . .447$

8c........................... . . 48

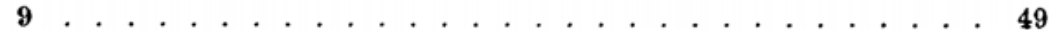

10 ........................ 50

11 . . . . . . . . . . . . . . . . . 50

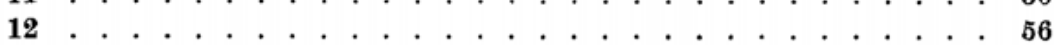

13 . . . . . . . . . . . . . . . . . . . . 56

14 . . . . . . . . . . . . . . . . . . 57

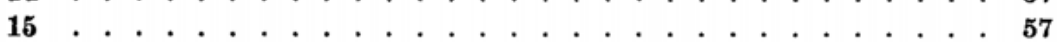




\section{Fritz Hintze}

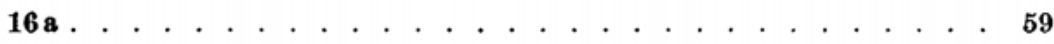

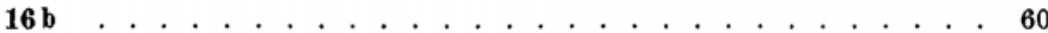

17 . . . . . . . . . . . . . . . 6 60

B. Opfertafeln von königlichen Angehörigen . . . . . . . . . . . . . 62

18 . . . . . . . . . . . . . . . . . . . . . . 62

19 . . . . . . . . . . . . . . . . . . . 63

$20 . . . . . . . . . . . . . . .663$

C. Nicht-königliche Opfertafeln _. . . . . . . . . . . . . . . . . 64

21 . . . . . . . . . . . . . . . . . . . . . . . . . . . . . . 64

22 . . . . . . . . . . . . . . . . . . 65

$23 . \ldots . . . . . . . . . . . .665$

3. Chronologische Utbersicht über die behandelten Texte . . . . . . . . . 66

4. Paläographische Tabelle . . . . . . . . . . . . . . . . . . . . . . 68

Anhang . . . . . . . . . . . . . . . . . . . . . . . . . . . . 69

I. Klassische Quellen zur Geschichte Meroes . . . . . . . . . . . . . . . . 69

1. Der Feldzug des Petronius . . . . . . . . . . . . . . . . . . . . . 69

a) Strabo, Geogr. XVII, 54 (820), (Meineke) . . . . . . . . . . . . . . . 69

b) Plinius, Nat. Hist. VI, $29(181,182)$. . . . . . . . . . . . . . . . . . . 70

c) Dio Cassius, Hist. LIV, 5-6 (Boissevain) . . . . . . . . . . . . . . . 70

2. Die Expeditionen Neros . . . . . . . . . . . . . . . . . . . . . . 70

a) Seneca, Nat. Quaest. VI, 8, 3 (A. Gereke) . . . . . . . . . . . . . . 70

b) Plinius, Nat. Hist. VI, $29(181,184-186)$. . . . . . . . . . . . . . . . 70

c) Dio Cassius, Hist. LXIII, 8. 1 (Boissevain) . . . . . . . . . . . . . . 71

3. Zur Lage von Daron . . . . . . . . . . . . . . . . . . . . . . . . 71

a) Plinius, Nat. Hist. VI, 29 (191) . . . . . . . . . . . . . . . . . . 71

b) Ptolemaeus, Geogr. IV, 7 (C. Müller) . . . . . . . . . . . . . . . . 71

II. Konkordanz der Fund-, Museums- und Publikationsnummern . . . . . . . 72 